\title{
Thomas Wynn, Sade's theatre: pleasure, vision, masochism
}

\section{Marisa Ferrarini}

\section{Q OpenEdition}

1 Journals

\section{Edizione digitale}

URL: http://journals.openedition.org/studifrancesi/7951

DOI: 10.4000/studifrancesi.7951

ISSN: 2421-5856

\section{Editore}

Rosenberg \& Sellier

\section{Edizione cartacea}

Data di pubblicazione: 1 juillet 2009

Paginazione: 405-406

ISSN: 0039-2944

\section{Notizia bibliografica digitale}

Marisa Ferrarini, «Thomas Wynn, Sade's theatre: pleasure, vision, masochism», Studi Francesi [Online], 158 (LIII | II) | 2009, online dal 30 novembre 2015, consultato il 13 janvier 2021. URL: http:// journals.openedition.org/studifrancesi/7951; DOI: https://doi.org/10.4000/studifrancesi.7951

Questo documento è stato generato automaticamente il 13 janvier 2021.

\section{(c) (i) (9)}

Studi Francesi è distribuita con Licenza Creative Commons Attribuzione - Non commerciale - Non opere derivate 4.0 Internazionale. 


\title{
Thomas Wynn, Sade's theatre: pleasure, vision, masochism
}

\author{
Marisa Ferrarini
}

\section{NOTIZIA}

THOMAS WYNN, Sade's theatre: pleasure, vision, masochism, Oxford, Voltaire Foundation

(SVEC 2007:02), 2007, pp. 224.

1 Suddiviso in sette capitoli («The theatre apparatus and masochistic spectatorship», pp. 13-32; «Tancrède and tout montrer», pp. 33-54; «Spectacle, artifice and genre», pp. 55-82; «Masochism and the Sadean tableau», pp. 83-111; «Limits of visual theatre», pp. 112-145; «Reading pleasure», pp. 146-158; «A theatre of the sublime», pp. 159-198), il suggestivo lavoro di Thomas Wynn, che presentiamo con imperdonabile ritardo, è una riabilitazione del teatro di Sade in piena regola. Ben venga! Se il Sade romanziere è stato difatti annoverato tra i più grandi scrittori dei Lumi, non altrettanto può dirsi del drammaturgo. Negletta o sprezzata dalla critica tanto da non essere inserita nelle Euvres complètes della Pléiade, la produzione drammaturgica sadiana, considerata da André Guyaux al contempo «du mauvais Sade et du mauvais théâtre, du théâtre d'imitation» (p. 5), necessitava di uno sguardo neutro.

2 Thomas Wynn ha centrato l'obiettivo: il suo è il primo studio che consideri la natura e le implicazioni dell'estetica drammaturgica di Sade e che definisca la qualità erotica di «spectatorship» nelle sue "pièces» sperimentali. Confutando l'assunto che lo sguardo fisso sia sadico, l'autore fa appello alla teoria cinematografica per dimostrare che Sade adatta testi teatrali contemporanei o precedenti per creare un'estetica nuova rispetto ai suoi scritti maggiori. Utilizza elementi concreti della scenografia (architettura, sedie, addobbi, macchine), per ridurre lo spettatore in uno stato di piena passività. Lungi dal riprodurre lo stile di lavori come Les Cent vingt journées de Sodome, i drammi sadiani preannunziano il modello masochistico teorizzato da Theodor Reik e Gilles Deleuze. 
3 Optando per l'estetica del tout montrer a discapito del linguaggio, Sade esalta in apparenza il senso esterno della vista. Ma in testi come Les Jumelles o il Boudoir lo sguardo è deludente, parziale e ridondante. Il che significa che il tout montrer richiede un tout lire. Non il vedere ma il leggere, ecco la tesi più interessante di Wynn. Il teatro di Sade parla all'immaginazione dello spettatore: snatura il suo sguardo fisico per dirigerlo altrove, ovvero al piacere di una meditazione clandestina.

4 Con puntuali riferimenti alla produzione teatrale erotica del XVIII secolo, l'apparato scenico e la storia della messa in scena, l'autore avanza un'ipotesi che ci pare di poter condividere pienamente: il teatro di Sade non è stato concepito per il grande pubblico, ma per l'immaginazione privata. Il suo teatro visionario è un esempio dell'estetica di fine Settecento del sublime, di un'estetica dell'ineffabile e del non rappresentabile.

Quel che non si rappresenta è ciò che fa paura. Chi ha paura di Sade? Nessuno. Godiamoci allora, senza patemi, i nostri sogni erotici, leggendo con piacere questo prezioso saggio di Thomas Wynn. 